\title{
Superior Real Estate Investment Performance: Enigma or Illusion? A Critical Review of the Literature
}

\author{
Crocker H. Liu, Terry V. Grissom and David J. Hartzell
}

\section{Introduction}

The purpose of this paper is to critique the existing empirical evidence on the investment performance of real estate relative to alternative asset categories. The key issue which guides this review of the investment performance literature is whether abnormal real estate returns are merely an illusion which arises from the shortcomings associated with various real estate performance studies or are the result of an omission of more fundamental factors. We suggest that any superior return is a short-run phenomenon, because, according to capital market theory, all assets should exhibit similar risk and return characteristics in the long run. If real estate continues to possess superior performance in the long run, then this implies that fundamental factors have been omitted from the real estate pricing model. Moreover, we will propose that a world in which the capital asset pricing model holds might be compatible with the existing evidence, because most of the prior studies have focused on total risk rather than on systematic risk. ${ }^{1}$ Consequently, all assets can plot on the security market line in equilibrium, given a CAPM world, regardless of whether one asset (portfolio) such as real estate dominates another asset (portfolio) such as stocks from a mean-variance perspective.

The remainder of this paper proceeds as follows. The first section summarizes the research to date on the investment performance of real estate. The studies surveyed include those which focus on direct investment in real estate as well as securities with real estate as 
an underlying asset. The next section describes the factors which might create the illusion of superior real estate returns but which are unaccounted for in the return measures of the articles surveyed. The final section summarizes and concludes the study.

\section{The performance of real estate relative to other assets}

The findings of most real estate performance studies are not comparable with one another, because some studies focus on evaluating the return or risk and return on one property type relative to common stocks, while other studies compare diversified real estate portfolios to common stocks or many investment alternatives. The various studies also use different return and risk measures to evaluate investment performance, since real estate data are frequently incomplete, with the sales price per period usually unknown due to thin trading. Typical return measures used include the internal rate of return, the cap rate, and the holding period return, while the usual risk measures examined include the standard deviation, the beta associated with the cap rate, and the holding period return.

The Wendt and Wong (1965) study is representative of research using the internal rate of return criterion to evaluate one type of real estate relative to common stock. This criterion is not adjusted for risk. Return performance of 20 FHA Section 608 apartments from the San Francisco Bay Area are compared to 76 randomly chosen industrial stocks from the COMPUSTAT tapes. The study finds that real estate outperforms common stock as a result of leverage and tax shelter effects. However, no superior real estate returns are found to exist when leverage and tax shelter are held constant.

Several shortcomings limit the validity of the performance implications arising from this study. The return measure used not only excludes risk but also assumes an implicit reinvestment rate. The conclusions also have limited generalization, since only one property 
type in one geographical location is examined. Special financing and tax benefits associated with FHA Section 608 properties also limit the results. Another limitation of this study is that the selling price of an apartment is assumed to equal eight times gross rent in the year of sale. Several purchase prices are also imputed using either an 8\% cap rate or the loan to value ratio.

The studies of Coyne, Goulet, and Piconni (1980), Kaplan (1985), and Robichek, Cohn, and Pringle (1972), in contrast to Wendt and Wong (1965), use risk-adjusted holding period returns rather than the internal rate of return ${ }^{2}$ Like Wendt and Wong however, these studies examine one property type relative to one or more alternative investments.

Coyne, Goulet, and Picconi (1980) demonstrate that residential real estate exhibits higher risk-adjusted returns relative to stocks and bonds. Both leveraged and unleveraged returns are examined over the period from 1969 to 1975. Bonds, existing real estate, and new real estate are found to have similar unleveraged risk-adjusted returns, while stocks, in comparison, exhibit lower returns. However, the introduction of leverage results in lower risk-adjusted returns to stocks and bonds, with both existing and new residential real estate risk-adjusted returns invariant to leverage. Another finding of this study is that residential real estate is an important diversification tool, since both new and existing residential real estate have a low or inverse correlation with stocks and bonds.

Both Robichek, Cohn, and Pringle (1972) and Kaplan (1985) find that farmland is also an effective portfolio diversification tool. Robichek, Cohn, and Pringle (1972) illustrate how 12 investment alternatives other than stocks and bonds can influence the construction of efficient portfolios. Farmland is the real estate alternative considered, with USDA data used to compute farm returns. Total returns earned on agricultural property are found to exceed the returns on all financial assets considered except for the S\&P industrials. However, farm 
real estate exhibits the highest average return per unit of total risk. The study also finds farm real estate returns are not significantly correlated with other investment media. Kaplan also discovers that farm real estate offers returns which are comparable to stock returns but less volatile.

The three preceding studies are consistent with the real estate performance studies based on the internal rate of return. Real estate still outperforms other investments, even after the return measure is corrected and risk is explicitly considered. Total risk, rather than systematic risk, is considered, since the standard deviation is used for these studies. However, the implications of these studies are limited, since only one property type is investigated. Study results are also limited for the Robichek et al. (1972), and Kaplan (1985) studies, because the USDA farm values used in both studies not only contain lagged adjustment periods but also include opinions of values in addition to actual prices. The portfolio implications of Kaplan (1985) are also tenuous, given that the means, variances, and covariances are not statistically meaningful. This phenomenon arises, since the number of time series observations is less than the number of parameters. None of the studies attempt to investigate why real estate outperforms alternative investment media.

Friedman (1971) and Webb and Sirmans (1980) also demonstrate that real estate not only offers diversification opportunities but, in addition, affords superior investment performance relative to other assets. The findings are more representative of real estate investment performance, since more than one property type is considered. The Friedman study differs from the Webb and Sirmans study with respect to both the return measure and the portfolio formation process employed. 
Friedman (1971) modifies the quadratic programming decision process of modern portfolio theory to address the integer problem associated with real estate. This integer problem arises since real estate is indivisible. A sample of 50 properties diversified with respect to geographical orientation and property type is used together with a random sample of 50 NYSE stocks. Annual holding period returns and variances are calculated for the years 1963 to 1968. Real estate portfolios are found to dominate stock portfolios with respect to a mean-variance criterion when each asset class is evaluated separately. This result holds both before and after taxes. Another finding is that a mixed-asset portfolio reduces portfolio risk, since real estate returns covary inversely to common stocks.

In contrast to Friedman, Webb and Sirmans (1980) compute real estate yields with cap rates. Thirteen different types of real estate are examined in addition to common stocks, bonds, and U.S. Treasury bills from 1951 to 1976 . The authors find that rates of return for different property types exceed returns on other financial media with lower risk. Another finding of the study is that leverage results in higher return and risk for all real estate considered. The study also indicates that heterogeneous risk and return characteristics are associated with different property types.

Several deficiencies temper the implications of the Friedman (1971) and the Webb and Sirmans (1980) studies. The data that Friedman uses contain only the initial 1963 market value and the sales price at the end of 1968. Interpolation of intermediate changes in market values is therefore required to calculate annual holding period returns, which in turn understates the total varibility in return. Systematic real estate risk is also understated, given that the real estate index used consists of the Boeckh construction cost indices combined with the American Appraisal Association Index. Construction cost indices 
overstate prices on existing real estate, since no depreciation is considered. In contrast, appraisals smooth returns, and therefore understate variability. Webb and Sirmans, on the other hand, do not interpolate market values. However, their use of cap rates understates the true equity return, since the property value is assumed to decline to the present value of equity. No appreciation component is explicitly considered, since the cap rate is analogous to a dividend yield for stocks. This suggests that the standard deviation of the cap rate understates total real estate risk to the extent that appreciation rather than income has historically accounted for most of the variability in total return.

Deficiencies with direct real estate investment data have prompted some authors to investigate real estate securities. Real estate securities considered include real estate investment trusts (REITs) and commingled real estate funds (CREFs). Controversy exists as to whether REITs have earned superior risk-adjusted returns relative to stocks. In contrast, risk-adjusted CREF returns are found to dominate stock returns. Smith and Shulman (1976) and Bums and Epley (1982) have both investigated REITS, while Miles and McCue (1984a) have evaluated CREFs.

Smith and Shulman (1976) compare the return performance for nine equity REITs relative to 15 closed-end investment companies. The geometric mean return and the intercept, the beta, and the $R 2$ from the single index model are used to compare the two types of investment vehicles with the S\&P Composite Index chosen as the market proxy. The major finding is that equity REITs and closed-end investment companies exhibit similar investment performance. Neither type of investment dominates over all subperiods examined. Another finding is that investing in an equity REIT is not useful for portfolio diversification. 
In contrast to Smith and Shulman (1976), Bums and Epley (1982) find that investing in real estate equities can increase portfolio returns. The main issue addressed is whether an efficient frontier consisting of real estate and stocks dominates the efficient frontier for a single asset type. The main finding is that a mixed-asset frontier dominates single-asset efficient frontiers with respect to mean-variance. Real estate returns dominate stock returns at the middle and lower risk-return levels. Stocks exhibit higher risk-risk-adjusted returns however, as one moves along the efficient frontier.

Different methodologies are partly responsible for the contradictory findings of Smith and Shulman (1976) relative to Burns and Epley (1982). Smith and Shulman use individual risk-adjusted performance measures. No correlations are computed for equity REITs relative to closed-end investment companies, therefore, their conclusion that no incremental benefit arises from real estate is questionable. Another questionable aspect of the Smith and Shulman study is that the same data are used to estimate the parameters and test the model. Although the Bums and Epley study does not suffer from the preceding methodological flaws, neither study addresses whether REITs are reliable proxies for direct real estate investment. No real estate performance insights obtain if REITs represent inadequate surrogates.

Mengden and Hartzell (1986) find preliminary evidence that REITs do not adequately represent real estate. Quarterly real estate returns computed with the PRIS A fund of Prudential are compared to the S\&P 500 and the Salomon Brothers equity REIT (EREIT) index. The major finding is that EREITs are hybrid securities with the price appreciation component positively related to general stock market movements, and the REIT dividend component positively correlated with real estate cash flows. This suggests that equity REIT shares might not be substitutes for direct real estate investment. However, a deficiency of this 
and all other studies which use CREF data is that the CREF returns are based on appraised values which understate the return variability. Another study limitation is that the extent to which REIT returns arise from capital market risk, and real estate market risk is not investigated.

Miles and McCue (1984a) empirically evaluate the impact of property type, region, and lease structure on CREF commercial real estate portfolio diversification. A proprietary CREF data base is analyzed over the 1973 to 1981 period with quarterly holding period returns computed relative to these three dimensions. The main finding is that commercial real estate diversification across both geographic regions and property types appears to be advantageous. Returns from various geographic regions and property types not only exhibit low correlations with stock and bond returns but also dominate stock from a risk-adjusted return perspective. Miles and McCue also find that systematic risk comprises only 10 to $15 \%$ of the total real estate risk. These results are tentative however, since the lease parameters are not held constant. The use of appraised values in lieu of market prices also affects the results, although Miles and McCue argue that minimal bias occurs, since the aggregation of appraisals does result in a fund price.

The existing literature reviewed thus far indicates that real estate exhibits equal or higher returns, with lower risk relative to common stocks and other assets. Real estate returns are also inversely related or not correlated to common stocks and bonds. This suggests that real estate is beneficial for portfolio diversification even if one accepts the argument that the risk and return for real estate is similar to stocks in the long run. REIT studies provide the only exception to this general consensus. However, shortcomings of various studies not only limit the applicability of results but also make comparison among studies difficult. These 
shortcomings include but are not limited to (1) noncomparable time periods; (2) incorrect return measures; (3) unreliable or insufficient data; (4) singular variance-covariance matrices of returns and questionable parameter estimates arising from more assets than time periods; (5) unrepresentative data such as data for a single property type or single geographical region; and (6) an assumed sales price, assumed appreciation growth rate, or appraised values in computing rates of return.

Zerbst and Cambon (1984) attempt to rectify some of these study deficiencies to facilitate comparison among real estate performance studies. Their main objective is to obtain conclusions about the performance of real estate relative to other asset classes. Only studies using either the IRR or holding period returns are reviewed, with all studies deflated to a real return perspective. Zerbst and Cambon find that except for REIT stocks, real estate outperforms stocks and bonds on both an unadjusted and risk-adjusted basis. This result is consistent with past empirical studies.

\section{The illusion of superior risk-adjusted real estate returns}

Several authors suggest that superior real estate investment performance is an illusion.3 “Abnormal” real estate returns should not arise, since arbitrage is expected to equalize investment alternatives. Reasons that these and other authors cite for superior real estate returns include:

- Inadequate theory and deficient valuation models,

- Omitted asset markets and misspecification of risk,

- Market imperfections such as thin trading, information/transaction costs, and divisibility, 
- Market segmentation arising from clientele effects, and

- Inflation risk.

However, little real estate research exists with respect to the influence of each factor on property returns. Following is an examination of each of these factors with respect to the performance and pricing of real estate.

\section{Inadequate Theory and Deficient Valuation Paradigms.}

Capital market theory presumes that all assets should possess similar risk-adjusted returns in equilibrium. Two alternative asset pricing models are associated with capital market theory. The capital asset pricing model (CAPM) of Sharpe (1964), Lintner (1965), and Mossin (1966) represents one equilibrium model. The CAPM describes the expected return on an asset as a function of its covariation with return on the market portfolio. This covariation is known as systematic risk. Investors are only compensated for bearing market risk in a CAPM world, since nonmarket risk is diversifiable. Every asset in a CAPM equilibrium is priced so that its risk-adjusted return falls exactly on the security market line.

The arbitrage pricing model (APT) provides an alternative explanation of the behavior of returns. Ross (1976) developed the APT to circumvent the restrictive CAPM assumption that the market portfolio is observable. For the APT to hold, all individuals believe that returns on assets are generated by a $\kappa$-factor linear model. This assumption is not required in a CAPM world. However, no presumption is made ex ante in the APT that one of the factors is the "market," although the factors are unknown a priori. In contrast to the APT, the CAPM requires not only that the market portfolio exist, but also that this portfolio be 
mean-variance efficient. All assets fall on a security hyperplane, given that a no arbitrage equilibrium exists.

Draper and Findlay (1982) question the appropriateness of the capital market theory and the CAPM for real estate, since the CAPM assumptions are violated, given the nature of the asset and the market within which real estate trades* They point out, however, that the CAPM is robust to unique property characteristics, since these attributes are amenable to mapping into risk-return space. Other market imperfections such as information, transaction costs, and indivisibility are regarded as short-term phenomena, since no entry restrictions exist for financial intermediaries to perform arbitrage. The appropriateness of the APT to real estate, on the other hand, is questioned, given the newness of the technique and the factor identification problem. Draper and Smith therefore advocate using either the hedonic pricing model (HPM) or the Hoag model for real estate.

Although Draper and Findlay question whether the CAPM is suitable for real estate, given the model's assumptions, their study does not empirically investigate whether the CAPM adequately predicts real estate returns. The empirical investigation of the CAPM with respect to real estate is necessary, since Friedman (1971) points out that violation of model assumptions is insufficient to invalidate a theory. Friedman advocates that the final test of a model is how well the model describes reality. The superior real estate performance studies reviewed might be compatible with a CAPM world, since these studies use total risk rather than systematic risk. All assets plot on the security market line in equilibrium regardless of whether these assets he on the mean-variance efficient frontier. Except for the study by Liu, Grissom, and Hartzell (1990), which is discussed in a subsequent section of this paper, no real estate study to date has relaxed the CAPM model assumptions to determine the resulting 
impact on real estate prices. Although Friedman (1971) and Findlay, et al. (1979) incorporate some of the unique real estate characteristics into the MPT, neither study derives a theoretical real estate pricing paradigm from their modified MPT models.

The hedonic pricing model (HPM) which Draper and Findlay advocate relates the price of a property to its physical, legal, and environmental attributes. Nothing in the HPM theoretical framework prohibits risk as a characteristic, although risk is not considered, since consumption theory rather than investment theory underlies the HPM. This consumption theory posits that consumers derive utility from the characteristics associated with a good rather than the good itself. Therefore, a demand and supply curve is assumed to exist for each attribute, with hedonic prices representing the marginal equilibrium price for each attribute.

Two functional forms of the HPM exist. The linear functional form is associated with Lancaster (1966), while the nonlinear form is associated with Rosen (1974) ${ }^{4}$ Both versions of the HPM focus solely on the local real estate market within which a property trades, with no interaction among asset markets considered in the price formation process. Another deficiency of the hedonic theory is that neither the attributes nor the functional form is known a priori. Which attributes are priced therefore is a function of which characteristics are chosen. The functional form chosen has serious implications with respect to market segmentation. These consequences are subsequently discussed.

Hoag (1980) proposes a multifactor model for income-producing real estate that captures the "spirit" of the HPM. The model incorporates financial characteristics in addition to physical characteristics and recognizes both macromarket and micromarket influences on real estate. In contrast, the traditional HPM recognizes only micromarket factors. Using a sample of 463 industrial properties, Hoag finds that industrial real estate exhibits risk and 
return characteristics which are comparable to common stock. This suggests that the superior risk-adjusted real estate return phenomenon is partly attributable to the smoothing tendencies of appraisals ${ }^{5}$ However, this study is consistent with other studies in finding that industrial real estate returns exhibit low correlations with stock returns.

The contrary findings of Hoag relative to other real estate studies arise in part from two factors. The Hoag model essentially simulates continuous trading for commercial real estate, which in turn increases the variability in prices. No liquidity premium is consequently required for a Hoag or HPM type of model. Another factor which biases the results in favor of similar risk-adjusted real estate and stock returns is the different levels of diversification used in the comparison process. The investment performance of a specific type of real estate — industrial properties — is compared to a well diversified stock portfolio (S\&P 500). This comparison is similar to evaluating one stock industry group such as gold stocks relative to the S\&P 500. A more appropriate comparison is to use either a real estate portfolio diversified across property types and economic bases against the S\&P 500 or to compare the industrial real estate funds to different stock industry groups on an individual basis. Comparison of a well diversified real estate fund with a stock fund might support existing empirical evidence.

Hoag does not substantiate that estimates from his model differ significantly from appraisals, although he alludes to the understatement of risk as the result of appraisal smoothing. The appraised price is related to the sales price, since the appraiser either has prior knowledge of the transaction price or the transaction price is executed with a knowledge of the appraisal. Another limitation of the Hoag study is that only one property 
type is analyzed over a relatively short period, with the same data used to develop and test the model.

Another theory which reflects the spirit of the hedonic pricing theory is the new equilibrium theory (NET) which Ibbotson. Diermeier, and Siegel (1984) propose to recognize both the risk and nonrisk characteristics in pricing assets. Risk characteristics include market risk, unanticipated inflation risk, real interest rate risk, and risk from a lack of diversification. Taxes and marketability costs, i.e., information costs, search and transaction costs, and divisibility costs are among the nonrisk factors cited. Clientele effects are also recognized in the NET framework, although no mention is made as to whether clientele effects result in an asset pricing premium. The NET theory is assumed to hold regardless of whether perfect markets (arbitrage) or imperfect markets (arbitrage) exist. No one is assumed to hold the market portfolio in a NET world, although all investors hold diversified portfolios.

The lack of a closed form quantitative model limits the usefulness of NET, although the theory is conceptually appealing. This limitation makes it difficult to empirically investigate the extent to which arbitrage opportunities arise from market imperfections. Another weakness of NET and also a drawback of the HPM and the Hoag model is that the portfolio formation process is not addressed, given market imperfections. The NET theory also does not address the question of why NET model development cannot proceed from relaxing the CAPM assumptions to account for market imperfections.

\section{Omitted Real Estate Asset Markets.}

Mayers (1972) and Roll (1977) both demonstrate that all assets fall on the security market line when the market proxy is correctly specified. Correct specification of the market 
portfolio implies that asset markets other than stocks and bonds, such as real estate, are explicitly recognized. A decomposition of the true market portfolio into component asset submarkets is therefore necessary to understand the nature of the omitted asset problem. Mathematically, the traditional Sharpe-Lintner-Mossin CAPM is

$$
\mathrm{E}\left(\widetilde{R_{j}}-r_{f}\right)=\lambda M \operatorname{cov}\left(\widetilde{R_{j}}, \widetilde{R_{m}}\right),
$$

where $M$ is the aggregate market value of all assets, and $X$ is the risk-aversion factor. But the dollar return on the market portfolio is decomposable as

$$
M \widetilde{R}_{m}=\sum_{i=1}^{p} M_{i} \widetilde{R}_{m_{i}}
$$

where $i$ represents the ith asset market. Substitution of (4) into (3) yields

$$
E\left(\tilde{R}_{j}-r_{f}\right)=\lambda\left\{\sum_{i=1}^{p} M_{i} \operatorname{cov}\left(\tilde{R}_{j}, \tilde{R}_{m_{i}}\right)\right.
$$

If $M_{S}$ is defined as the aggregate market value of a security market proxy such as the S\&P 500, then (5) is alternatively expressed as

$$
E\left(\tilde{R}_{j}-r_{f}\right)=\lambda M_{s} \operatorname{cov}\left(\tilde{R}_{j},-R_{m_{s}}\right)+\left\{\lambda \sum_{i \neq s} M_{i} \operatorname{cov}\left(\tilde{R}_{j}, \tilde{R}_{m_{i}}\right)\right\}
$$

where the term in brackets $\{$.$\} represents the return from the omitted asset markets. If the$ covariance of the return on asset $j$ with the return on the $i$ th asset submarket is zero, where $i$ does not represent the security submarket $S$, i.e.,

then (6) degenerates to

$$
\operatorname{cov}\left(\tilde{R}_{j}, \tilde{R}_{m i}\right)=0 \quad \forall_{1}, i \neq s j=1, \ldots, N,
$$

$$
E\left(\tilde{R}_{j}-r_{f}\right)=\lambda M_{s} \operatorname{cov}\left(\tilde{R}_{j}, \tilde{R}_{m s}\right) .
$$


The key issue therefore is not whether the true market portfolio is required, as Roll (1977) contends, but whether the term in brackets is significantly different from zero for the jth asset class.

Both Fama and Schwert (1977a) and Stambaugh (1982) empirically demonstrate that omitted asset markets do not pose a problem in estimating common stock returns. However, neither study investigates whether the omitted real estate asset market is important with respect to real estate returns. Another related issue not addressed in either study is whether the S\&P 500 adequately represents the real estate market. Real estate is not totally omitted, since the S\&P 500 includes real estate related components such as homebuilding, financials, and building materials.

Miles and Rice (1978) show that omitted real estate markets do affect real estate returns. Miles and Rice (1978) construct a new market proxy, which consists of stocks, farm real estate, and human capital, to test the CAPM; they find that higher betas result for farm returns when the new market index is used relative to the S\&P 500. However, the study does not investigate whether abnormal risk-adjusted returns exist for real estate after accounting for systematic real estate market risk. Liu et al. (1990) extend the Miles and Rice (1978) study by examining if superior risk-adjusted real estate returns exist after incorporating omitted real estate markets. More specifically, the study considers whether the composition of the market portfolio leads to different inferences on real estate performance. As a point of departure, the study investigates if the omitted asset phenomenon results in a biased measurement of investment performance. The study finds that ranking investment performance is not a meaningless exercise, even if measurement bias exists. Another study finding is that different inferences on real estate investment performance do not necessarily 
result, given variations in the composition of the market proxy. Liu et al. also find that both the omitted asset phenomenon and smoothing bias account in part for superior real estate investment performance.

\section{Market Imperfections: Transaction and Information Costs, Taxes, and Illiquidity.}

Ibbotson and Siegel (1984) find evidence that “abnormal” real estate returns occur even after various types of real estate are included in the market portfolio. The authors therefore argue that nonmarket risks are priced. These market imperfections include high transaction and information costs, taxes, and illiquidity. However, no attempt is made to determine which nonmarket risk factor has a premium associated with it. Although the real estate literature recognizes that these imperfections distinguish real estate from other assets, few real estate studies rigorously investigate the relationship of these imperfections to return. Only the relationship of taxes and illiquidity to real estate returns exists in the real estate literature.

The combined impact of taxes and leverage do not adequately account for superior real estate returns. Wendt and Wong (1965) find that the return on apartments relative to common stock is almost identical when cash flows are adjusted for taxes and financing. Certain limitations cited earlier, however, limit the interpretation of the study's conclusions. The study conclusions are further limited, since the contribution of leverage is not separated from tax shelter. Ricks (1969) rectifies this deficiency of Wendt and Wong through an investigation of the independent and joint impact of leverage and taxes on real estate IRRs. However, no attempt is made to compare returns for different property types to common stock. Ricks finds that financing raises the return, while taxes lower the return, with the 
positive leverage effect tending to offset the negative tax effect in general. However several deficiencies inherent in the Wendt and Wong study also temper the conclusions of Ricks. Ricks imputes certain parameter values for the equity investor and assumes that no change occurs in either operating income or price over time. Returns are therefore hypothetical. Other limitations of the study are that the IRR is used as the measure of return and that risk is not explicitly considered.

Webb and Sirmans (1980) also find that leverage partly accounts for higher rates of return to different property types. In contrast to Ricks (1969) and Wendt and Wong (1965) however, risk is explicitly considered with cap rates used in lieu of IRR as the measure of return. Higher risk-adjusted real estate returns are found to exist regardless of the leverage effect. Unfortunately, the tax aspect is not considered.

The real estate literature also recognizes that higher real estate returns and lower risk could arise from illiquidity. Illiquidity is reflected in one of several ways, including an allowance for thin trading, the use of appraisals, and the use of either the HPM or the Hoag model. The Friedman (1970) study exemplifies the first alternative. An allowance for thin real estate markets is incorporated in the analysis through a $15 \%$ decrease in the real estate sales price, with no justification given as to why $15 \%$ is chosen. In contrast to Friedman, most real estate performance studies reviewed use appraisals in lieu of market prices to obviate the need for a liquidity premium. Roulac and King (1977, p. 63) rationalize the use of appraised values as surrogates for prices as follows:

Many assert that stock prices are "facts”, whereas real estate appraisal values are opinions, largely because a transaction at that price could confidently be executed for the former but not the latter. Others would dispute this on two grounds, the effects of 
large block trades on prices and...the presumed illiquidity in the real estate markets. When properly priced, an investment property transaction can be properly executed, just as a stock order at a price above the market may not be executed.

The implicit assumption which underlies this argument is that no systematic appraisal bias exists. This assumption is tenuous when individual properties are analyzed, although the law of large numbers might eliminate appraisal bias for aggregated data.

Cole, Guilkey, and Miles (1986) compare sales prices to appraised values on a mean absolute differences basis and find preliminary evidence that is consistent with the contention of Roulac and King (1977). The major finding is that no significant appraisal bias exists after major outliers are removed although a large confidence interval exists around any appraisal. Appraisal bias is thus a concern with respect to individual properties. The study unfortunately does not investigate whether this bias still exists when appraised values are aggregated into property types or regions.

Hoag (1980) questions the validity of appraisals in dealing with thin trading, given his finding that real estate risk is comparable to stock risk when continuous real estate trading is simulated. However, the study does not investigate the bias from an appraisal model relative to the Hoag model. The models differ in that the appraisal process adjusts prices of comparable properties to the subject property, while the Hoag model constructs a representative property from comparables and then adjusts the subject property to this representative property.

None of the three alternative real estate methods for dealing with illiquidity directly adjusts systematic or total risk. The methods thus contrast methods proposed in the finance 
literature for dealing with thin trading bias. Scholes and Williams (S—W) (1977) and Dimson (1978) both propose techniques for estimating systematic risk of infrequently traded assets which essentially increase beta for thin trading and therefore increase the return. A downward bias in systematic risk thus occurs for infrequently traded assets. Systematic risk is not examined in real estate with respect to illiquidity, given the lack of adequate time series real estate market returns until recently and questions about the appropriateness of the CAPM to real estate.

\section{Market Segmentation.}

Another type of market imperfection which might account for superior risk-adjusted returns on real estate relative to stocks is the clientele effect. Clientele effects arise either as the result of different sets of investors known as clienteles associated with different components of return —income versus capital appreciation —or different types of asset markets. Each clientele group represents a market segment. The existence of clienteles is a consequence of self-imposed barriers, legal and institutional constraints, geographical impediments, or a combination of these factors.

Liu, Grissom, and Hartzell (1990) theoretically investigate the impact of dividend clienteles on real estate returns, given that illiquidity exists. Intuitively, the authors argue that illiquidity represents a proportionate cost on the resale but not on the income component of return. An "illiquidity tax" is therefore associated with real estate capital appreciation but not the cap rate. This asymmetrical cost situation is the reverse of the tax-induced dividend effect in the finance literature, since a higher tax is associated with dividends relative to capital gains. Thus, the consequences of illiquidity for real estate returns in a no-tax or tax-neutral world should inversely mirror the consequence of tax-induced clienteles in finance. As 
expected, the study finds that illiquidity causes real investors to bid up the price of real estate the higher the expected income yield. Moreover, illiquidity is found to reduce the extent to which investors hold real estate in their portfolios. Given the ambitious nature of the study, the authors leave much room for further refinements and extensions including looking at illiquidity from a multiperiod context, assuming that a stochastic risk-free rate exists. This might yield further insights into optimal hedging strategies involving the use of real estate in mixed asset portfolios.

The key issue in Liu, Grissom, and Hartzell (1990) of whether dividend clienteles affect returns is distinct from the issue of whether investor clienteles exist. The real estate literature notes that different investor clienteles are associated with different real estate market tiers. The first tier consists of institutional investors investing in income properties. Individual investors trading in single family residential homes represent the second tier. However, these two tiers are not mutually exclusive, because some clientele participation across tiers is present. Both Webb (1984) and Miles and McCue (1982) find that institutional investors favor income-producing properties. No equity interests in single family homes exist, although mortgages on homes are a part of institutional portfolios. Miles and McCue (1982, p. 187) therefore recognize that a super risk premium might arise for certain property types:

Recent institutional interest has focused in office and retail properties to the exclusion for the most part of residential. Residential properties. . . are perceived as more risky for institutional investors. . . Consequently, one would expect the relative yields of office and retail properties to be lower relative to residential properties due to the large market impact of institutional buyers. 
No attempt is made however to test this proposition.

The existence of a segmentation between the commercial real estate market and the single family home market is puzzling. No reason is given why institutional investors cannot purchase large blocks of residences, since this is analogous to purchasing an apartment complex. Institutional investor avoidance or unwillingness to take an equity position in homes might arise from pressures relating to their fiduciary responsibilities. Specifically, the type of revenue-earning assets acquired should approximately match expected institutional liabilities incurred or contractual obligations. Homes provide little if any income, with most of the return associated with resale. This resale component is less certain and is also subject to illiquidity, which implies that institutional investors might experience difficulties in timing the resale to coincide with contractual obligations. Diermeier, Freundlich, and Schlarbaum (1985) posit that institutional investors do not take equity positions in single family residences given the lack of a direct, profitable vehicle to currently purchase single family homes in large quantities for institutional portfolios and the substitutability issue of consumption for investment. Bosch (1986) demonstrates, however, that the consumption decision is separable from the investment decision if a real estate rental market exists, since individuals can adjust their consumption flows. Bosch shows that the optimal portfolio of residential real estate is independent of consumption. Everyone holds the same portfolio of financial and real estate assets, given that a rental market exists. The equilibrium price of residential real estate is derived, conditional on an efficient rent market.

The real estate literature is more developed with respect to segmentation within the commercial real estate market or the housing market, with more literature available on the latter than the former. Market segmentation is presumed to arise, given that buyers typically 
restrict their search process to certain neighborhoods due to monetary considerations and concerns dealing with the quality of amenities. A hedonic model is typically used to investigate segmentation, with stratification evidenced if prices associated with housing attributes vary for identical properties located in different geographic areas.

In one of the few studies on commercial market segmentation, Grissom, Hartzell, and Liu (1987) investigate whether a segmented market exists for industrial real estate with respect to risk and return characteristics using the APT framework. The authors find that regional markets exist for industrial real estate, because different risk attributes influence property returns in various industrial submarkets even if the same pricing paradigm holds. In addition to this, the study finds that the number of priced risk factors differs across regions, with some risk factors systematic across two or more regions, while other risk factors are found to be systematic only within a given region. Further, some of the risk factors priced are unique to a given region, while ubiquitous risk factors are not compensated for in all regions. A limitation of the study is that appraised values which understate the factor loadings, are used. In addition the use of factor analysis in estimating the APT parameters has been questioned on the grounds that there is no unique factor solution. Therefore, a researcher can obtain whichever set of factors he is looking for by continuing to rotate the "axes." Consequently, a more modem test of the APT applied to real estate, using the technology in McElroy and Burmeister (1988), in which the unknown random factors of factor analysis are replaced with observed macroeconomic variables, might provide additional insights, as well as verification of the phenomena that Grissom et al. observed. A question which arises from the findings of Grissom et al. is why segmentation should exist if institutional investors are not restricted as to type of property and areas of the country in which they can invest. 
The real estate literature is more developed with respect to housing market segmentation, with the empirical studies consistently finding evidence in support of housing market segmentation. The implicit assumption underlying each of these studies is that the HPM is portable across submarkets so that identical attributes are priced in each neighborhood. Controversy exists however over whether more precise value estimates arise through focusing solely on the micromarket within which a property trades. Richardson and Thalheimer (1982), Schnare and Stmyk (1976), and Sonstalie and Portney (1980) find that estimating separate pricing equations for each submarket does not increase the predictive power of intra-SMS A variations in housing prices. In contrast, both Goodman $(1978,1981)$ and Dale-Johnson (1982) find evidence that market segmentation improves valuation estimates.

A limitation of all the preceding HPM studies is that the functional form is not known a priori. This poses a problem, since the HPM functional form determines whether segmentation exists. A nonlinear HPM is a sufficient condition for market segmentation. In contrast, theoretically market segmentation should not occur if a linear HPM is used. Another deficiency with these studies is that the housing submarkets are unknown ex ante. Therefore, different studies use different attributes to stratify markets, with segmentation variables that consumers perceive to exhibit inelastic supply, inelastic demand, or both usually chosen. Stratification schemes are therefore arbitrary. No study investigates why super price premiums should occur if buyers have access to all submarkets.

A key question which arises if segmented property markets or property and capital markets are present is whether super risk premiums exist. Liu et al. (1980) investigate the interrelationship of stock and real estate clienteles, focusing on the extent to which real estate 
securitization has integrated these market structures. The existence of super risk premiums would suggest that more securitization is needed to complete the markets. This leads to the related question as to how to repackage real estate attributes to arbitrage away any premium if no investment barriers exist. The authors find evidence that the commercial real estate market is segmented from the stock market. However, the primary cause of segmentation varies and is a function of the market proxy chosen and of whether appraised values or imputed sales prices are used. Indirect barriers are found to represent the prime segmentation catalyst when appraised values are employed. In contrast, inconclusive evidence exists as to whether segmentation is the result of indirect barriers or legal constraints when imputed sales prices are evaluated. This is not surprising, given that a problem with the study is that imputed sales prices are measured with error, and therefore the power of the tests is weakened.

\section{Inflation Risk.}

The real estate literature recognizes that a premium for inflation could also account for the superior risk-adjusted returns associated with real estate relative to stocks and bonds. However, although most studies show that real estate returns possess an inflation premium, controversy exists as to whether real estate hedges against both anticipated and unanticipated inflation.

Merton (1973) theoretically demonstrates that differences among expected returns on assets can exceed variations in systematic market risk, given a multiperiod context, if the risk-free rate is not constant over time. This is due to the fact that investors are not only exposed to systematic market risk, but are also exposed to risk from unfavorable shifts in the opportunity set. Consequently, differentials in asset returns can occur due to the fact that 
different assets do not provide equivalent hedges against intertemporal changes in the portfolio opportunity set.

Fama and Sehwert (1977b) use the Merton CAPM to evaluate the ability of several alternative asset classes to hedge against inflation. Residential real estate is found to hedge against both expected and unanticipated inflation, while common stocks do not hedge against either type of inflation. This finding is consistent with the theory in Merton (1973), namely, that different assets do not provide equivalent inflation hedges. Several problems, however, limit the study findings. First, the home purchase price component of the CPI is used as the real estate proxy, which might overstate the degree to which real estate provides an inflation hedge, since the CPI is used as the measure of inflation. Another limitation which Fama and Sehwert recognize is that only capital gains are associated with their real estate series. The series is also limited to only FHA insured residences, which currently account for only 7\% of all home sales according to the Bureau of Labor Statistics. Further, only lower priced homes are represented in the FHA data, given the existence of legal constraints on the price ceilings of loans.

In contrast to Fama and Schwert (1977b), Miles and McCue (1984a) find that real estate hedges against anticipated but not unanticipated inflation when individual, commercial real estate returns from a large CREF are examined. However, the returns that the authors use are based on appraised values and as such are subject to smoothing. Smoothing tends to exert an upward bias on the correlation of the rate of inflation to quarterly real estate returns. Another problem with the study is that inflation continuously trends upward over the time period chosen. Potential bias also exists since an ex post commercial paper rate which 
incorporates default risk rather than bids on Treasury Bills is used as a proxy for anticipated inflation.

Brueggeman, Chen, and Thibodeau (1984) rectify the deficiency with the anticipated inflation proxy present in Miles and McCue (1984a). Overall returns on two CREFs are used rather than property-specific CREF data. The study results are consistent with Miles and McCue in that commercial real estate hedges against anticipated but not unexpected inflation. Another study finding is that commercial real estate outperforms corporate bonds, even after inflation risk and omitted real estate markets are accounted for. Like the Miles and McCue study, however, a limitation of the study is that appraised values are used, which Liu et al. (1989) argue could increase the likelihood of superior returns for real estate in the form of positive Jensen alphas.

In contrast to other real estate inflation studies, Fogler, Granito, and Smith (1985) find inconclusive evidence as to whether inflation is priced. Two hypotheses are proposed to account for the superior risk-adjusted returns of real estate relative to other assets. Both hypotheses presume real estate returns are positively related to unanticipated inflation. The random event hypothesis posits that a change in the perceived sensitivity of returns to unanticipated inflation does not result in a structural change to expected returns. In contrast, the hedge demand hypothesis postulates that inflation risk is priced. Although some support is found for the hedge demand hypothesis, the power associated with the empirical tests is weak. The study also suffers from the same deficiencies inherent in the Fama and Schwert (1977b) study, since the home purchase price component of the CPI is used as the real estate proxy, which might bias the results in favor of the hedge demand hypothesis. The interesting conjecture which Fogler et al. make, but do not test, given data limitations, is that an inflation 
premium may exist only in certain time periods, depending on whether real estate is in vogue. They contend that if investing in real estate is fashionable, and a period of rising inflation exists, then inflation is priced. However, no inflation premium will arise if investing in real estate is not considered faddish, even though an inflationary economic environment exists.

Hartzell, Hekman, and Miles (1987) revaluate the findings of Miles and McCue (1984a), focusing on the response of various real estate return classifications to inflation. These classifications include returns according to property type, property size, and the economic growth of SMS As, in addition to overall real estate returns. Returns are computed from the Miles and McCue (1984a) database over a larger time period, to recognize both inflation and disinflation environments, with bids on T-bills used in lieu of the commercial paper rate to derive anticipated inflation. In contrast to Miles and McCue (1984a), the study finds that both anticipated and unanticipated inflation are priced with respect to commercial real estate. This result also holds for industrial and office property types, in addition to larger properties. In contrast, retail properties do not adequately hedge against either anticipated or unanticipated inflation. Nor is the inflation hedging advantage found from grouping properties into portfolios representing differential SMS A growth rates. Once again, a limitation of the study is that appraised values are employed in lieu of market prices.

\section{Summary and conclusions}

Empirical evidence suggests that "abnormal” returns exist for real estate. Such evidence is purported to represent an enigma, since arbitrage should equalize investment alternatives. Controversy arises as to whether this conundrum is attributable to shortcomings of various real estate performance studies or to more fundamental factors. The current study argues that, from the perspective of economic theory, superior real estate performance arises 
from an omission of certain fundamental factors, including (1) inadequate theory and deficient valuation models, (2) omitted asset markets and misspecification of risk, (3) market imperfections such as thin trading, information/transaction costs, and divisibility, (4) market segmentation arising from clientele effects, and (5) inflation risk. However, little theoretical or empirical real estate research exists concerning whether additional return premiums are associated with these factors. Most literature on the preceding factors deals with financial assets. Extant real estate literature suggests omitted real estate markets and inflation risk both result in additional premiums, but do not totally account for abnormal returns. Some evidence also exists that illiquidity might explain superior real estate performance. The current study suggests that a CAPM world is compatible with the real estate performance studies reviewed, since the studies focus on total risk rather than systematic risk. Therefore, all assets could still plot on the security market line in equilibrium, given a CAPM world, regardless of whether one asset (portfolio) dominates another asset (portfolio) from a mean-variance perspective. 


\section{Notes}

1. Even those studies which have used systematic risk in demonstrating that real estate outperforms stock might be compatible with the CAPM, because these studies are based on appraised data which Giliberto (1988) has shown leads to a positive return bias for real estate.

2. Although real estate performance is investigated, the primary purpose of these studies is to demonstrate the incremental contribution that real estate makes to either a stock or stock and bond efficient portfolio.

3. These authors include Draper and Findlay (1982), Hoag (1980), Jaffe and Sirmans (1984), Miles and McCue (1984), Roulac (1976) and Zerbst and Cambon (1984), among others.

4. Lancaster develops a demand oriented theory from a household production perspective. The spirit of the Lancaster work is that consumers play a dual role of producers. Goods are purchased as inputs into the housing production function of a consumer for ultimate characteristics. Lancaster assumes that a linear consumption technology exists which is additive and homogeneous of degree one. A linear specification of the hedonic price function thus results. The nonliner functional form of Rosen (1974), in contrast to a Lancastrian world, is based on a market orientation with buyers and sellers explicitly recognized.

5. Giliberto (1988) offers theoretical support for this finding by demonstrating that a positive return bias will always exist if appraisal errors are serially independent. 


\section{References}

Bosch, J.C. "Portfolio Choices, Consumption, and Prices in a Market with Durable Assets.” Journal of Financial Research 9:3 (1986), 239-250.

Brennan, Michael J. “Taxes, Market Valuation, and Corporate Financial Policy.” National Tax Journal 23:4 (1970), 417—428.

Brueggeman, William, Andrew Chen, and Thomas Thibodeau. "Real Estate Investment Funds: Performance and Portfolio Considerations.” AREUEA Journal 12:3 (1984), 333-354.

Bums, William, and Donald Epley. "The Performance of Portfolios of REITS and Stocks.” Journal of Portfolio Management 8:3 (1982), 37-42.

Cole, Rebel, David Guilkey, and Mike Miles. “Toward an Assessment of the Reliability of Commercial Appraisals.” Appraisal Journal 54:3 (1986), 422—432.

Coyne, Thomas J., Waldemar M., Goulet, and Mario J., Picconi. "Residential Real Estate Versus Financial Assets.” Journal of Portfolio Management 7:1 (1980), 20-24.

Dale-Johnson, David. “An Alternative Approach to Housing Market Segmentation Using Hedonic Price Data.” Journal of Urban Economics 11:3 (1982), 311-332.

Diermeier, Jeffrey J., J. Kurt Freundlich, and Gary G. Schlarbaum. “The Role of Real Estate in a Multi-Asset Portfolio.” In: Tom Sale (ed.), Real Estate Investing. New York: Dow Jones, Irwin, 1985.

Dimson, Elroy. "Risk Measurement When Shares are Subject to Infrequent Trading.” Journal of Financial Economics 7:2 (1979), 197-226.

Draper, Dennis W. and M. Chapman Findlay III. “Capital Asset Pricing and Real Estate Valuation.” AREUEA Journal 10:2 (1982), 152-183. 
Fama, Eugene F. and G. William Sehwert. “Asset Returns and Inflation.” Journal of Financial Economics 5:2 (1977), 115—146.

Fama, Eugene F. and G. William Sehwert. "Human Capital and Capital Market Equilibrium.” Journal of Financial Economics 4:1 (1977), 95-125.

Findlay, M. Chapman III, Carl W. Hamilton, Stephen D. Messner, and Jonathan S. Yormark. “Optimal Real Estate Portfolios.” AREUEA Journal 1:2 (1979), 298-317.

Fogler, H. Russell, Michael R. Granito, and Laurence R. Smith. "A Theoretical Analysis of Real Estate Returns.” Journal of Finance 40:3 (1985), 711—719.

Friedman, Harris C. “Real Estate Investment and Portfolio Theory.” Journal of Financial and Quantitative Analysis 6:2 (1971), 861—874.

Giliberto, S. Michael. “A Note on the Use of Appraisal Data in Indexes of Performance Measurement.” AREUEA Journal 16:1 (1988), 77—83.

Goodman, Allen C. "Submarkets within Urban Areas: Definitions and Evidence.” Journal of Regional Science 21:2 (1981), 175—185.

Goodman, Allen C. “Hedonic Prices, Price Indices, and Housing Markets.” Journal Urban Economics 5:4 (1978), 471-484.

Grissom, Terry V., David Hartzell, and Crocker H. Liu. “An Approach to Industrial Real Estate Market Segmentation and Valuation Using the Arbitrage Pricing Paradigm.” AREUEA Journal 15:3 (1987), 199-219.

Hartzell, David, John Hekman, and Mike Miles. "Real Estate Returns and Inflation.” AREUEA Journal 15:1 (1987), 617-637.

Hoag, James W. “Towards Indices of Real Estate Value and Return.” Journal of Finance 35:2 (1980), 569-580. 
Ibbotson, Roger G. and Laurence B. Siegel. "Real Estate Returns: A Comparison with Other Investments.” AREUEA Journal 12:3 (1984), 219—242.

Ibbotson, Roger G., Jeffrey J. Diermeier, and Laurence B. Siegel. “The Demand for Capital Market Returns: A New Equilibrium Theory.” Financial Analysts Journal 40:1 (1984), 22-33.

Jaffe, Austin J. and C.F. Sirmans. “The Theory and Evidence on Real Estate Financial Decisions: A Review of the Issues.” AREUEA Journal 12:3 (1984), 378-400.

Kaplan, Howard M. “Farmland as a Portfolio Investment.” Journal of Portfolio Management 11:2 (1985), 73-78.

Kelleher, Dennis G. "How Real Estate Stacks Up to the S\&P500.” Real Estate Review 6:2 (1976), 60-65.

Lancaster, K.J. “A New Approach to Consumer Theory.” Journal of Political Economy 74:2 (1966), 132-157.

Lintner, John. "Security Prices, Risk, and Maximal Gains from Diversification.” Jounal of Finance (1965) 587—615.

Liu, Crocker H., David J. Hartzell, Terry V. Grissom, and Wylie Grieg. “Alternative Rationales for Superior Real Estate Investment Performance: An Empirical Reinterpretation of Prior Research.” Working Paper, New York University, 1990.

Liu, Crocker H., David J. Hartzell, Terry V. Grissom, and Wylie Grieg. “The Composition of the Market Portfolio and Real Estate Investment Performance.” AREUEA Journal 18:1 (1990), 49-75. 
Liu, Crocker H. Terry V. Grissom, and David J. Hartzell. “The Impact of Market Imperfections on Real Estate Returns and Optimal Investor Portfolios.” AREUEA Journal (forthcoming).

Liu, Crocker H. David J. Hartzell, Wylie Grieg, and Terry V. Grissom. "The Integration of the Real Estate Market and the Stock Market: Some Preliminary Evidence.” Journal of Real Estate Finance and Economics 3:3 (1990), 261-282.

McElroy, Marjorie B. and Edwin Burmeister. “Arbitrage Pricing Theory as a Restricted Nonlinear Multivariate Regression Model.” Journal of Business and Economic Statistics 6:1 (1988), 29—42.

Mengden, Anne E. and David Hartzell. "Real Estate Investment Trusts: Are They Stocks or Real Estate?” Salomon Brothers Inc., August 27, 1986.

Merton, Robert C. “An Intertemporal Capital Asset Pricing Model.” Econometrica, 41:5 (1973), 867-887.

Miles, Mike and Arthur Esty. “How Well Do Commingled Real Estate Funds Perform?” Journal of Portfolio Management 8:2 (1982), 62—68.

Miles, Mike and Michael Rice. “Toward a More Complete Investigation of the Correlation of Real Estate Investment Yield to the Rate Evidenced in the Money and Capital Markets: The Individual Investor's Perspective.” The Real Estate Appraiser and Analyst 44:6 (1978), 8-19.

Miles, Mike and Tom McCue. “Commercial Real Estate Returns.” AREUEA Journal 12:3 (1984), 355-377.

Miles, Mike and Tom McCue. "Diversification in the Real Estate Portfolio.” Journal of Financial Research 7:1 (1984), 57—68. 
Mossin, Jan. “Equilibrium in a Capital Asset Market.” Econometrica 34:4 (1966) 786-83.

Richardson, David H. and Richard Thalheimer. "On the Use of Grouping Methods in the Analysis of Residential Housing Markets.” Regional Science and Urban Economics 12: (1982) $285-304$.

Ricks, Bruce R. “Imputed Equity Returns on Real Estate Financed with Life Insurance Company Loans.” Journal of Finance 24:5 (1969), 921—937.

Robichek, Alexander A., Richard A. Cohn, and John J. Pringle. "Returns on Alternative Investment Media and Implications for Portfolio Construction.” Journal of Business 45:3 (1972), 427—443.

Roll, Richard. “A Critique of the Asset Pricing Theory’s Tests.” Journal of Financial Economics 4:2 (1977), 129—176.

Rosen, Sherwin. "Hedonic Prices and Implicit Markets: Product Differentiation in Pure Competition. Journal of Political Economy 82:1 (1974), 34—55.

Ross, Stephen. “The Arbitrage Theory of Capital Asset Pricing.” Journal of Economic Theory 13:3 (1976), 341-360.

Roulac, Stephen E. “Can Real Estate Returns Outperform Common Stocks.” Journal of Portfolio Management 2:2 (1976), 26—43.

Roulac, Stephen E. and Donald A. King, Jr. "Institutional Strategies for Real Estate Investment.” Journal of Portfolio Management 3:4 (1977), 58—65.

Sack, Paul. “Management of Real Estate Portfolio.” In: Sumner Levine (ed.), The Investment Manager's Handbook. New York: Dow-Jones, Irwin. 1980.

Schnare, Ann B. and Raymond J. Struyk. "Segmentation in Urban Housing Markets." Journal of Urban Economics 3:2 (1976), 146-166. 
Scholes, Myron and Joseph Williams. "Estimating Betas from Nonsynchronous Data." Journal of Financial Economics 5:3 (1977), 309-327.

Sharpe, William F. "Capital Asset Prices: A Theory of Market Equilibrium Under Conditions of Risk.” Journal of Finance 19:3 (1964), 425-42.

Smith, Keith V. and David Shulman. "The Performance of Equity Real Estate Investment Trusts.” Financial Analysts Journal 32:5 (1976), 61—66.

Sonstelie, Jon C. and Paul R. Portney. "Gross Rents and Market Values: Testing the Implications of Tiebout’s Hypothesis.” Journal of Urban Economics 7:1 (1980), 102118.

Stambaugh, Robert F. "On the Exclusion of Assets from Tests of the Two Parameter Model: A Sensitivity Analysis.” Journal of Financial Economics 10:3 (1982), 237-268.

Webb, James R. “Real Estate Investment Acquisition Rules for Life Insurance Companies and Pension Funds: A Survey.” AREUEA Journal 12:4 (1984), 495-520.

Webb, James, R. and C.F. Sirmans. "Yields and Risk Measures for Real Estate, 1966-1977.” Journal of Portfolio Management 7:1 (1980), 14-19.

Wendt, Paul F. and Sui N. Wong. "Investment Performance: Common Stocks vs. Apartment Houses.” Journal of Finance, 20:4 (1965), 633-646.

Zerbst, Robert H. and Barbara H. Cambon. "Real Estate: Historical Returns and Risk.” Journal of Portfolio Management 10:3 (1984), 5-20. 